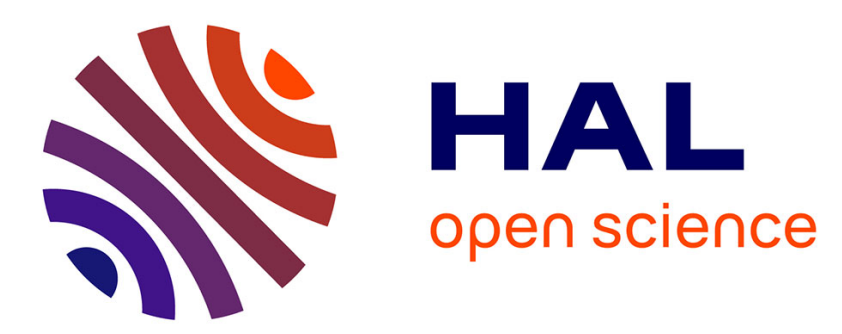

\title{
Influence of Nanostructuration on the Vibrational, Electronic and Optical Properties of CrSi2 Thin Films
} Adrien Moll, Patrick Hermet, Jean-Louis Bantignies, Christophe Candolfi, Bertrand Lenoir, David Maurin, Michel Ramonda, Erwan Oliviero, Nicole Fréty

\section{To cite this version:}

Adrien Moll, Patrick Hermet, Jean-Louis Bantignies, Christophe Candolfi, Bertrand Lenoir, et al.. Influence of Nanostructuration on the Vibrational, Electronic and Optical Properties of CrSi2 Thin Films. Journal of Physical Chemistry C, 2020, 124 (51), pp.28267-28276. 10.1021/acs.jpcc.0c08740 . hal-03373384

\section{HAL Id: hal-03373384 \\ https://hal.science/hal-03373384}

Submitted on 11 Oct 2021

HAL is a multi-disciplinary open access archive for the deposit and dissemination of scientific research documents, whether they are published or not. The documents may come from teaching and research institutions in France or abroad, or from public or private research centers.
L'archive ouverte pluridisciplinaire HAL, est destinée au dépôt et à la diffusion de documents scientifiques de niveau recherche, publiés ou non, émanant des établissements d'enseignement et de recherche français ou étrangers, des laboratoires publics ou privés. 


\section{Influence of Nanostructuration on the Vibrational,}

\section{Electronic and Optical Properties of $\mathrm{CrSi}_{2}$ Thin}

\section{Films}

Adrien Moll $^{1}$, Patrick Hermet ${ }^{1}$, Jean-Louis Bantignies ${ }^{2}$, Christophe Candolfi ${ }^{3}$, Bertrand Lenoir ${ }^{3}$, David Maurin $^{2}$, Michel Ramonda $^{4}$, Erwan Oliviero $^{l}$, Nicole Fréty ${ }^{1 *}$

${ }^{1}$ Institut Charles Gerhardt Montpellier, UMR5253, CNRS, Université de Montpellier, Montpellier 34095, France

${ }^{2}$ Laboratoire Charles Coulomb, UMR 5221, CNRS, Université de Montpellier, Montpellier 34095, France

${ }^{3}$ Institut Jean Lamour, UMR 7198 CNRS - Université de Lorraine, Nancy 54011, France

${ }^{4}$ Michel Ramonda, Centrale de Technologie en Micro et nanoélectronique, Université de Montpellier, Montpellier 34095, France

*Corresponding author

Keywords: chromium silicide, thin film, nanostructuration, amorphous semiconductor, electron scattering, vibrational properties, optical properties 


\begin{abstract}
We report a detailed experimental investigation of the influence of the formation of nanocrystallites on the vibrational, electronic and optical properties of $\mathrm{CrSi}_{2}$ thin films. Both amorphous and nanostructured thin films were investigated by means of electrical resistivity, Hall effect measurements as well as Raman and infrared spectroscopies. We show that both types of films exhibit a semiconducting-like behavior, with the notable difference that the high defect concentrations in amorphous films act as hole donors, modifying the electronic band structure and optical constants. The effect of the film thickness on electrical properties is well captured by the Fuchs-Sondheimer model indicating a decrease in the charge carrier mean free path, likely due to the formation of amorphous/nano-crystallite interfaces that contribute to strongly scatter the charge carriers. Raman spectroscopy performed on nano-crystallized thin films evidences the presence of a Raman-active mode at $229 \mathrm{~cm}^{-1}$ and confirms DFT calculations predicting a mode at $248 \mathrm{~cm}^{-1}$, the observation of which had remained elusive so far in polycrystalline $\mathrm{CrSi}_{2}$. Measurements of the refractive index and dielectric constants of amorphous thin films show a very high refractive index in the mid-IR range. Our results illustrate how the controlled growth of nano-crystallites can be used to tailor the electronic, vibrational and optical properties of amorphous thin films.
\end{abstract}

\title{
1. Introduction
}


Transition metal silicides have been considered over the last decades as important technological materials, particularly in microelectronics ${ }^{1-3}$. Among their numerous advantages, their high melting point, high thermal stability, and compatibility with silicon-based microelectronic devices explain the strong interest for these compounds. Moreover, the low cost and large abundance of silicon enables to consider large-scale development using its wellmastered processing technologies. While most of these compounds are metallic, some of them contain transition metals from group VI to VIII elements and exhibit a semiconducting or semimetallic behavior possibly accompanied by exotic magnetic or topological properties such as $\mathrm{FeSi}_{2}, \mathrm{MnSi}_{1.7}, \mathrm{Ru}_{2} \mathrm{Si}_{3}$ and $\mathrm{CoSi}^{4,5-7}$.

Among these semiconducting silicides, chromium disilicide, $\mathrm{CrSi}_{2}$, is a $p$-type narrow-bandgap material that remains chemically and thermally stable up to at least $1000 \mathrm{~K}$ under air ${ }^{8,9}$. Due to its indirect bandgap measured to be about $0.35 \mathrm{eV}^{10,11}$, low temperature coefficient of resistance ${ }^{12-14}$ and promising thermoelectric power factor $\left(P F=\alpha^{2} / \rho\right)$ resulting from low electrical resistivity, $\rho$, and high Seebeck coefficient, $\alpha,{ }^{15,}{ }^{16}$, this compound has been considered for various applications ranging from IR detection 10, 17, 18, thin-film resistor in integrated circuits ${ }^{12-14}$, contact material in nanosystems ${ }^{19}$, Schottky junctions ${ }^{20,21}$ or for thermoelectric power generation at high temperatures ${ }^{15,16}$.

Due to the high number of potential applications, a wealth of studies of the electrical properties of $\mathrm{CrSi}_{2}$ in bulk polycrystalline and single-crystalline forms and in thin films have been reported. However, widely differing results were obtained, with $\rho$ values ranging from $0.21 \mathrm{~m} \Omega . \mathrm{cm}^{22}$ to $18.5 \mathrm{~m} \Omega . \mathrm{cm}^{23}$ at room temperature. This wide range of values can be explained by differences in deposition methods, heat treatments, film thickness and Cr:Si stoichiometry. Studies of thin films obtained by co-sputtering of $\mathrm{Cr}$ and $\mathrm{Si}^{24-27}$, evaporation ${ }^{13,28,29}$ or pulsed laser deposition 
${ }^{22,30}$ at room temperature, have all reported the formation of an amorphous material. Partial or full crystallization of thin films were observed by annealing between 420 and $870 \mathrm{~K}$, resulting in an increase in the $\rho$ values $24-26,28,29,31-33$. One possibility would be that high annealing temperature and duration may induce the formation of cracks due to thermal expansion and crystallographic orientation mismatches between the thin film and the substrate ${ }^{25,}{ }^{26}$. Nevertheless, the increase in the electrical resistivity with crystallization is mostly explained by charge carrier scattering at the amorphous phase - nanocrystallites interface ${ }^{24,28,29}$ and by the presence of acceptor-like extended or localized states near the valence band in the amorphous material disappearing by crystallization ${ }^{32,33}$. Thus, the electrical properties of thin films are highly sensitive to the process route, heat treatments applied and to the nature of the substrate. Gong et al ${ }^{26}$ studied the influence of annealing on the electrical properties of sputtered $\mathrm{CrSi}_{2}$ thin films deposited on $\mathrm{Si}(100)$ wafer with $\mathrm{SiO}_{2}$ sublayer with thicknesses spanning the $40-90$ nm range. An increase in $\rho$ was observed after annealing $1 \mathrm{~h}$ at $573 \mathrm{~K}$ under nitrogen atmosphere, a behavior attributed to the full crystallization of the thin film with the formation of wide boundaries surrounding columnar grains. Recently, Burkov et al ${ }^{24}$ reported the study of $\mathrm{CrSi}_{2}$ thin films with a thickness of $100 \mathrm{~nm}$ deposited by sputtering on oxidized $\mathrm{Si}$ wafer. Partial crystallization from 500 to about $900 \mathrm{~K}$ was shown to lead to the formation of non-percolating nano-crystallites within the amorphous matrix that behave as scattering centers. Concomitantly, enhanced $\alpha$ values were observed in this heterogeneous material, tentatively ascribed to an energy-filtering mechanism of holes.

Despite the abundant literature data available for $\mathrm{CrSi}_{2}$, the physical properties of the amorphous phase have been only scarcely investigated $22,25,26,29,32,34$. To the best of our knowledge, the vibrational properties were only measured by Koudelka et al ${ }^{27}$, while optical 
properties have not been reported yet. Amorphous materials are characterized by the absence of long-range atomic order with a high number of dangling bonds acting as dopants. Moreover, disorder drastically alters the phonon properties, strongly scatters charge carriers, thereby reducing their mobility, and triggers the formation of long tails of localized states in the band gap of amorphous semiconductors. These effects can significantly impact the vibrational, optical and electrical properties of the materials. The control of interface charge carriers and phonons scattering mechanisms by structural defects or further nanostructuration is of great importance for some applications such as thermoelectricity ${ }^{35,36}$. It is therefore of prime interest to determine the influence of microstructure variations on the transport properties, a necessary step towards further development of nanostructured $\mathrm{CrSi}_{2}$ for applications.

Here, we report a detailed experimental study of the influence of nano-crystallization on the vibrational, electronic and optical properties of $\mathrm{CrSi}_{2}$ amorphous thin films elaborated by sputtering. Vibrational properties were studied by Raman scattering which evidenced, for the first time, the existence of a new vibrational mode of crystalline $\mathrm{CrSi}_{2}$, which was previously predicted by DFT calculations ${ }^{37}$. The electrical properties of both amorphous and nanostructured thin films were measured for film thicknesses ranging between 12 and $480 \mathrm{~nm}$. We show that the effect of film thickness on the electrical properties is well captured by the Fuchs-Sondheimer model. The modification of the electronic structure and optical properties due to nanocrystallization are highlighted for the first time by IR reflectance and transmittance measurements.

\section{Methods}


2.1. Film elaboration. $\mathrm{CrSi}_{2}$ thin films were deposited by sputtering with thickness ranging from 12 up to $480 \mathrm{~nm}$ on either glass substrates, $\mathrm{CaF}_{2}$ substrates, or $p$-type $\mathrm{Si}(100)$ wafers (BT electronics, B doping), depending on the characterization technique used. Prior to deposition, the substrates were cleaned with acetone and ethanol in an ultrasonic bath during 1 min and dried under $\mathrm{N}_{2}$. In the case of $\mathrm{Si}$ wafer, the native oxide layer was etched in a hydrofluoric acid solution (10 vol.\%, $30 \mathrm{~s})$ and a $\mathrm{SiO}_{2}$ sublayer with a thickness of $30 \mathrm{~nm}$ was pre-deposited for electrical measurements. Scanning electron microscopy (SEM) observations evidenced a continuous $\mathrm{SiO}_{2}$ sublayer, preventing a direct contact between the $\mathrm{CrSi}_{2}$ deposited film with the Si wafer. A Plassys MP4505 RF magnetron sputtering (13.56 MHz) equipment was used for thin film deposition. The distance between the $\mathrm{CrSi}_{2}$ target (Neyco $99.95 \%$ purity, 3 in. diameter) and the substrate was about $5 \mathrm{~cm}$. The base pressure in the chamber was $2 \times 10^{-6}$ mbar before deposition. Argon gas (99.999\% purity) was used to create the plasma with a controlled pressure of 5.1 Pa. The sputtering power was set to $120 \mathrm{~W}$. The target and the substrate were water cooled during sputtering. The film thickness was controlled by measuring the height of a step made by lift-off process using atomic force microscopy (AFM). Thermal treatments of thin films were performed during $1 \mathrm{~h}$ at $723 \mathrm{~K}$ in dynamic vacuum $\left(10^{-4}\right.$ mbar) with a heating rate of $100 \mathrm{~K} \mathrm{~h}^{-1}$ and natural cooling. The temperature was controlled with a K-type thermocouple next to the sample.

2.2. Microstructural characterization. High Resolution Transmission Electron Microscopy (HRTEM) cross-section observations were performed using a JEOL 2200FS-200 kV equipment at the MEA platform, University of Montpellier. Prior to these observations, the $\mathrm{CrSi}_{2}$ film deposited on a $\mathrm{Si}(100)$ substrate was prepared in cross-section by focused ion beam (FIB) on a FEI Strata DB 235 at IENM - Lille. Before etching the sample with the gallium ion beam, a 
platinum layer, and a carbon layer were first deposited to protect sample surface. Atomic force microscopy (AFM) was performed in tapping mode with a Dimension 3100 AFM microscope from Brücker Instruments equipped with a nanoscope 3A quadrex. The tip used was a silicon pointprobe-plus from Nanosensors. Images of sizes $2 \times 2 \mu \mathrm{m}^{2}$ and $5 \times 5 \mu \mathrm{m}^{2}$ were recorded. Data were treated with the software Gwyddion ${ }^{38}$ to determine the mean square roughness, $R_{m s}$.

2.3. Electrical measurements. Low-temperature in-plane electrical resistivity and Hall Effect measurements were performed from 80 up to $230 \mathrm{~K}$ for samples deposited on a $\mathrm{Si} / \mathrm{SiO}_{2}$ substrate in a Van der Pauw configuration with an Ecopia HMS 5000 equipment under air. Good electrical contacts were achieved using indium. A magnetic field of $0.5 \mathrm{~T}$ was used for Hall effect measurements. At high temperatures $(300-700 \mathrm{~K})$, in-plane electrical resistivity of thin films deposited on glass substrate was measured with a ZEM-3 (Ulvac-Riko) apparatus under a low helium pressure using a conventional four-probe method. Electrical contacts were ensured by deposited thin gold tracks on the thin films. The thin films were maintained in a vertical position using a dedicated sample holder (Ulvac-Riko).

2.4. IR and Raman measurements. Reflectance and transmittance infrared (IR) measurements were carried out with a $161 \mathrm{~nm}$ thick film deposited on a transparent $\mathrm{CaF}_{2}$ substrate. The measurements were performed on the same film before and after annealing. IR spectra were recorded using a Bruker IFS $66 \mathrm{~V}$ Fourier transform spectrometer covering the $800-7500 \mathrm{~cm}^{-1}$ spectral range. A black body source, a $\mathrm{KBr}$ beam splitter, and a Mercury-Cadmium-Telluride (MCT) detector were used. Room-temperature transmittance and reflectance measurements were performed using the reflection of a Transmittance Bruker accessory (A510 Q/T) with an angle of incidence $(\theta)$ of $11^{\circ}$ placed in the sample compartment of the FTIR spectrometer. Micro-Raman spectroscopy experiments were conducted at room temperature on a $480 \mathrm{~nm}$ thick $\mathrm{CrSi}_{2}$ film 
grown on $\operatorname{Si}(100)$ substrate after annealing at $873 \mathrm{~K}$ for 20 min under Ar. A LabRam Aramis spectrometer from Horiba Jobin-Yvon was implemented using a He-Ne laser $(\lambda=633 \mathrm{~nm})$. The beam power was set to $7.3 \mathrm{~mW}$ to avoid sample thermal heating.

\section{Results and discussion}

\subsection{Thin film microstructure and effect of thermal treatment}

The TEM cross-section images of a $45 \mathrm{~nm}$ thin film (deposited on $\mathrm{Si}(100)$ wafer) before and after annealing performed at $723 \mathrm{~K}$ for $1 \mathrm{~h}$ are shown in Figure 1. A typical columnar structure is observed for the as-deposited thin film with the presence of the native silicon oxide sublayer $(\sim 5$ $\mathrm{nm}$ ) at the substrate/film interface (Figure 1a). The electron diffraction pattern mainly consists in a large halo characteristic of the amorphous nature of the thin film (Figure 1b). The halo is

located between inter-reticular distances of 1.80 and $2.37 \AA$. The intense and regular spots observed are characteristic of the single-crystalline $\mathrm{Si}(100)$ substrate.

The annealing step does not alter the columnar structure which is maintained (Figure 1c). A modification of the microstructure of $\mathrm{Si}$ is observed at the $\mathrm{Si} / \mathrm{CrSi}_{2}$ interface by TEM. This is due to $\mathrm{Cr}$ diffusion into the $\mathrm{Si}$ substrate up to about $10 \mathrm{~nm}$ as estimated by Electron Dispersive X-ray Spectroscopy (EDXS) analysis. Nevertheless, the diffraction pattern shows additional spots, evidencing the crystallization of the hexagonal $\mathrm{CrSi}_{2}$ phase (Figure 1d). Their low intensity is attributed to the nanometer size of the crystallites, ranging from 3 to $10 \mathrm{~nm}$. A weak diffuse halo is still observed. The annealed thin film is therefore made of $\mathrm{CrSi}_{2}$ nano-crystallites embedded in an amorphous matrix. 

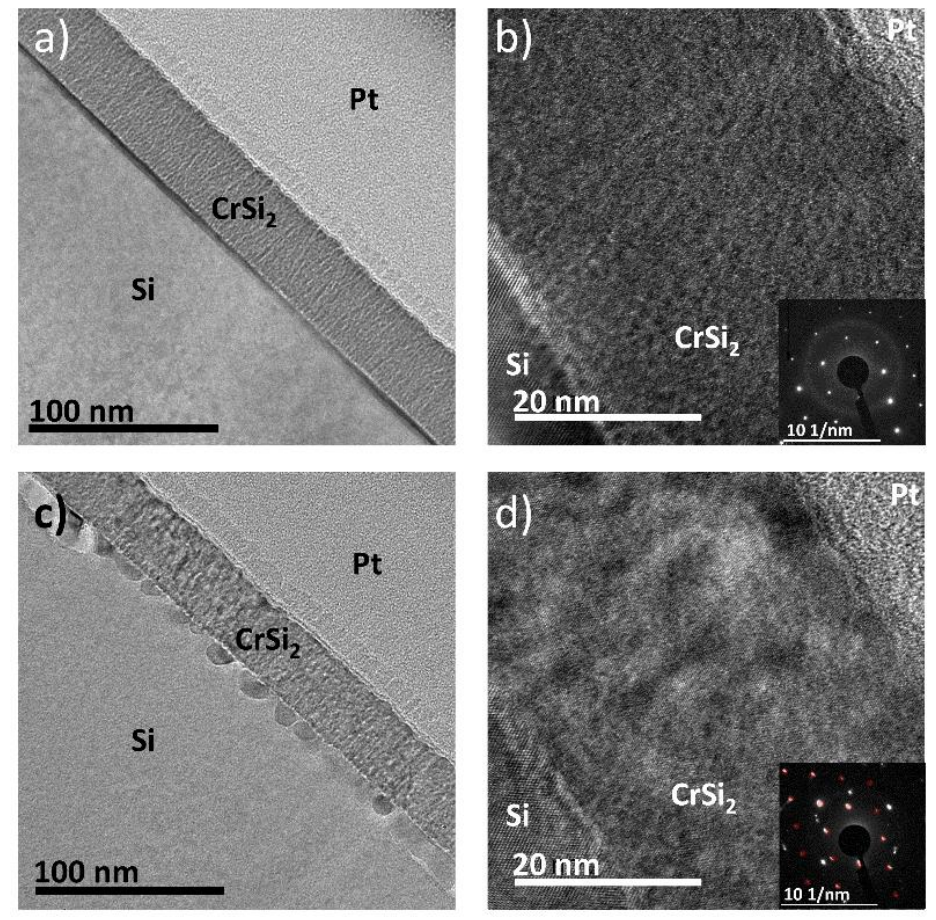

Figure 1. TEM cross-sectional images of a $45 \mathrm{~nm}$ thin film deposited on a Si substrate: a) and b) as deposited, c) and d) after thermal treatment at $723 \mathrm{~K}$ for $1 \mathrm{~h}$, and electronic diffraction patterns in the insets. The spots due to the $\mathrm{Si}(100)$ substrate are colored in red on the diffraction pattern of Figure d).

Because both the phonon and electron transport mechanisms can be modified by the surface roughness of the thin films, the root-mean-square roughness $R_{m s}$ of the surface of the thin film was determined from the $2 \times 2 \mu \mathrm{m}^{2}$ AFM images for the as-deposited and annealed films with thicknesses varying from 12 up to $164 \mathrm{~nm}$ (Figure S1 in Supporting Information). The evolution of $R_{m s}$ as a function of the film thickness is reported in Figure 2. The $R_{m s}$ values of the asdeposited amorphous thin films are low, varying from 0.5 up to $0.8 \mathrm{~nm}$, and only weakly depend on the film thickness. After annealing, the $R_{m s}$ values of the nanostructured thin films only slightly increase, with values ranging between 0.7 and $1.2 \mathrm{~nm}$. 


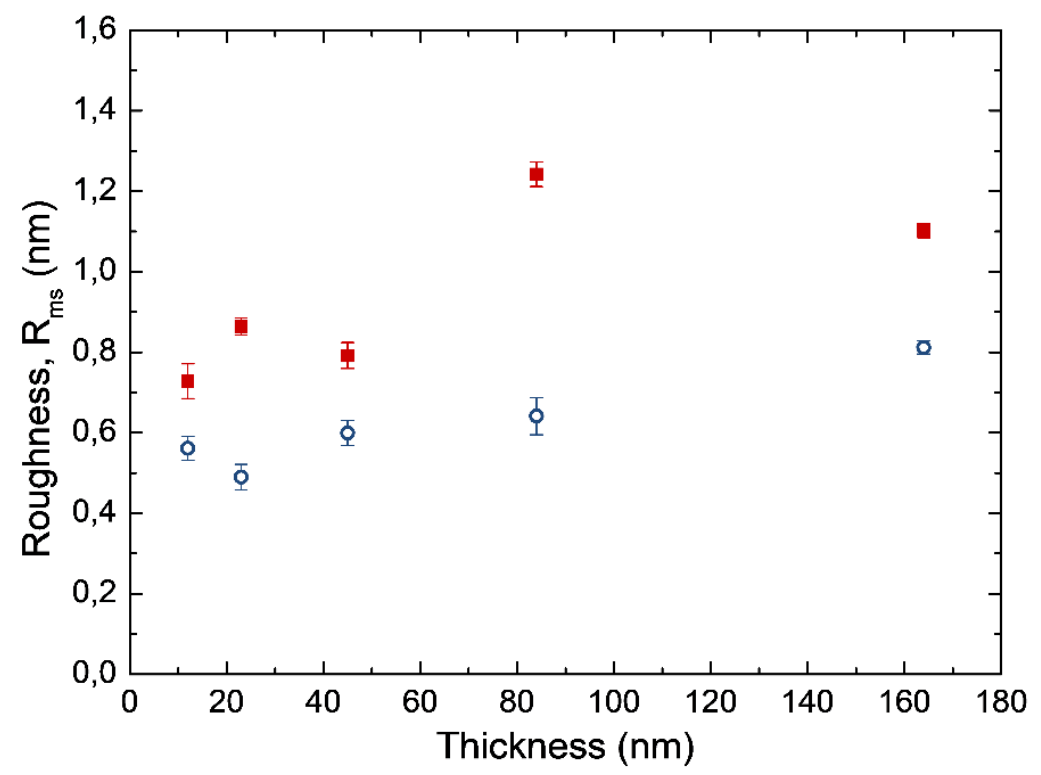

Figure 2. Roughness $R_{m s}$ of amorphous (as-deposited) and nanostructured (annealed) $\mathrm{CrSi}_{2}$ thin films. ○ Amorphous films $\square$ Nanostructured films.

\subsection{Vibrational properties of $\mathrm{CrSi}_{2}$ thin films}

At the Brillouin zone center, the optical phonon modes of crystalline $\mathrm{CrSi}_{2}$ can be classified according to the irreducible representations of the $\mathrm{D}_{6}$ point group $\Gamma=\mathrm{A}_{1}+2 \mathrm{~A}_{2}+4 \mathrm{E}_{2}+4 \mathrm{E}_{1}+$ $3 \mathrm{~B}_{2}+2 \mathrm{~B}_{1}$. The $\mathrm{E}_{1}$ representation is both infrared and Raman active. The $\mathrm{A}_{1}$ and $\mathrm{E}_{2}$ representations are Raman active while the $\mathrm{A}_{2}$ representation is only infrared active. The $\mathrm{B}_{1}$ and $\mathrm{B}_{2}$ representations are silent. The frequencies of the silent modes have never been measured so far but they have been predicted by DFT calculations ${ }^{37}$ at 204 and $300 \mathrm{~cm}^{-1}$ (B $\mathrm{B}_{1}$ modes), and at 238, 284 and $393 \mathrm{~cm}^{-1}$ ( $B_{2}$ modes). The two infrared $A_{2}$ modes have been reported in the literature to be around 295 and $375 \mathrm{~cm}^{-1}$, in agreement with calculations.

Raman spectra of as-deposited and annealed thin films of $480 \mathrm{~nm}$ thickness grown on $\mathrm{Si}(100)$ are shown in Figure 3 and are compared with that obtained for powders ${ }^{37}$. For the as-deposited thin film, no lines are observed in agreement with its amorphous state, as previously reported by 
Koudelka $e a^{27}$. After annealing, the spectrum is composed of 6 Raman lines centered at 229, 300, 350, 394, 408 and $453 \mathrm{~cm}^{-1}$. The contributions between 300 and $410 \mathrm{~cm}^{-1}$ have been reported in the literature on $\mathrm{CrSi}_{2}$ thin films ${ }^{11,39}$, powders ${ }^{37}$ and single crystal ${ }^{40}$ and their frequency positions are clearly identified (see Ref. ${ }^{37}$ for the assignment of these Raman lines). The Raman line at $229 \mathrm{~cm}^{-1}$ is unambiguously identified for the first time on a $\mathrm{CrSi}_{2}$ film to be the $\mathrm{E}_{1}$ mode predicted by DFT calculations ${ }^{37}$. Although this line has already been observed in single crystal ${ }^{40}$ and powders ${ }^{37}$, its significantly weaker intensity prevented any definitive conclusion to be drawn about its frequency position. Interestingly, an additional tiny Raman line can also be identified at $248 \mathrm{~cm}^{-1}$ in Fig. 3. This line had been previously observed only in powders ${ }^{37}$, but with a very low intensity. The fact that this line is experimentally observed on different samples and confirmed by first-principles calculations makes its assignment and position firmly established. The broad line observed at $453 \mathrm{~cm}^{-1}$ has never been reported in literature, should it be on thin films, powders or single-crystalline $\mathrm{CrSi}_{2}$. DFT calculations assign the $440-450 \mathrm{~cm}^{-1}$ range as either $E_{2}$ modes or longitudinal optical (LO) $E_{1}$ modes ${ }^{37}$. At this stage, these two possible modes cannot be distinguished, which will require additional polarization-like experiments. 


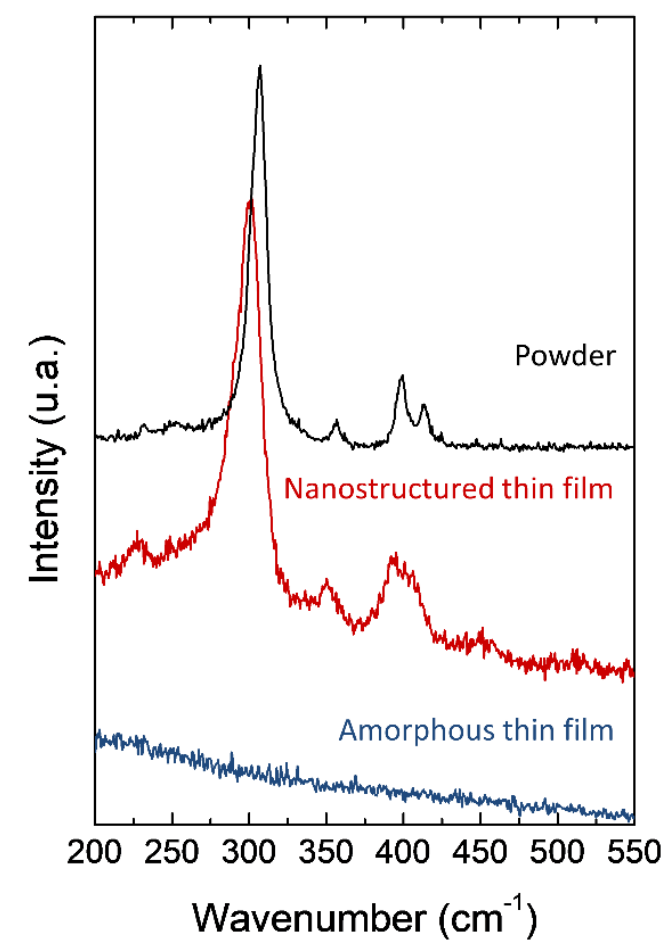

Figure 3. Raman spectra of amorphous and nanostructured $\mathrm{CrSi}_{2}$ thin films compared with that obtained on powders ${ }^{37}$.

\subsection{Electronic properties of $\mathrm{CrSi}_{2}$ thin films}

\subsubsection{Evolution of the electrical resistivity with temperature}

The electrical resistivity, $\rho$, was measured from 300 to $685 \mathrm{~K}$ for a $\mathrm{CrSi}_{2}$ thin film grown on glass substrate with a thickness of $480 \mathrm{~nm}$. As shown in Figure 4, $\rho$ does not significantly vary from room temperature up to $520 \mathrm{~K}$, with a mean value of $0.46 \mathrm{~m} \Omega . \mathrm{cm}$. This behavior, characterized by a low temperature coefficient of resistance $(\mathrm{TCR}=1 / \rho \times \partial \rho / \partial T)$, is consistent with an amorphous material ${ }^{41}$. It should be noted that contrary to crystalline materials, a positive or negative TCR is not related to either a metallic or semiconducting state ${ }^{41}$. Above $520 \mathrm{~K}, \rho$ significantly increases up to $0.94 \mathrm{~m} \Omega . \mathrm{cm}$ at $685 \mathrm{~K}$. This behavior, similar to that reported previously for amorphous $\mathrm{CrSi}_{2}$ thin films with a transition at temperatures ranging from 450 to 
$600 \mathrm{~K}^{24-26,28,29}$, was attributed to the partial crystallization of the material. Upon cooling, $\rho$ remains practically temperature-independent with a mean value of $0.94 \mathrm{~m} \Omega . \mathrm{cm}$.

The electrical resistivity of bulk polycrystalline $\mathrm{CrSi}_{2}$, reported by Dasgupta et al. ${ }^{42}$, increases from $0.9 \mathrm{~m} \Omega . \mathrm{cm}$ at $300 \mathrm{~K}$ to a maximum value of $1.8 \mathrm{~m} \Omega . \mathrm{cm}$ at $550 \mathrm{~K}$, before decreasing at higher temperatures. These two distinct regimes correspond to the degenerate and intrinsic regime, respectively, of a semiconductor ${ }^{43}$. Our results also show a positive TCR for $\mathrm{CrSi}_{2}$ nanostructured films, about $5 \times 10^{-4} \mathrm{~K}^{-1}$ around $300 \mathrm{~K}$, in contrast to as-deposited amorphous films, but with values significantly lower than those reported in bulk $\mathrm{CrSi}_{2}\left(\sim 4 \times 10^{-3} \mathrm{~K}^{-1}\right.$ at $300 \mathrm{~K})^{42}$. These results suggest that the nanostructured films are already above the percolation threshold after annealing at $700 \mathrm{~K}$. This is in agreement with the work of Gladun et al. ${ }^{31}$, where a positive TCR for $\mathrm{Cr}_{x} \mathrm{Si}_{1-x}$ films $(x=0.115$ to 0.30 ) was measured after annealing at a temperature that was varying with $x$ (at $573 \mathrm{~K}$ for $x=0.3$ with TCR $3 \times 10^{-4} \mathrm{~K}^{-1}$ ). They notably showed that this effect was related to the percolation of $\mathrm{CrSi}_{2}$ crystallites formed within the amorphous matrix during annealing for $x>0.11$. 


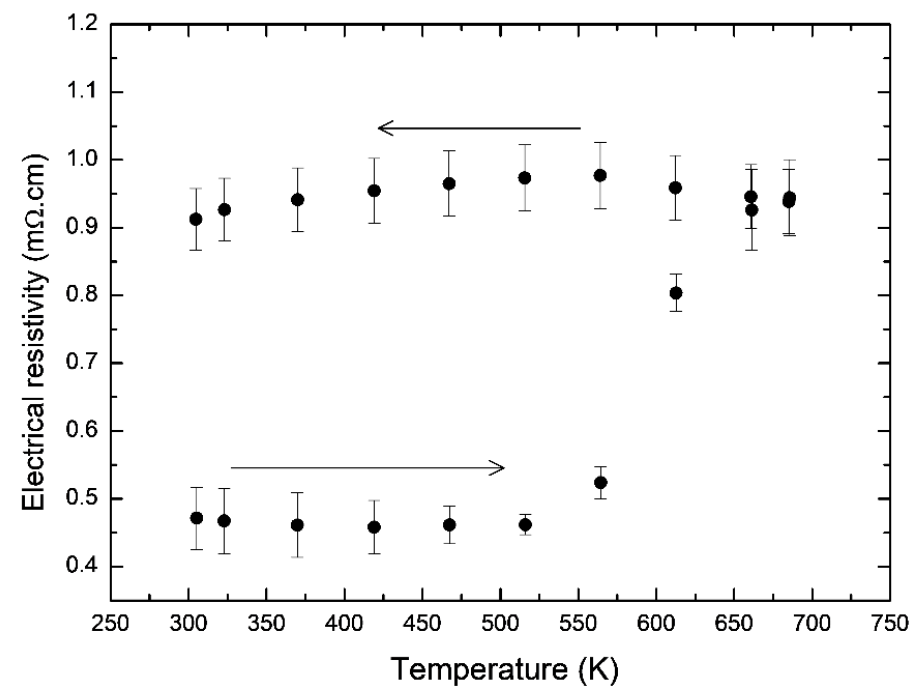

Figure 4. Electrical resistivity $\rho$ as a function of temperature for a $\mathrm{CrSi}_{2}$ thin film with a thickness of $480 \mathrm{~nm}$.

To better understand the origin of the increase in $\rho$ after partial crystallization, the effective charge carrier density, $p_{H}$, and mobility, $\mu_{H}$, were measured by Hall effect between 80 and 230 K. For the amorphous films, both $p_{H}=1.0 \times 10^{23} \pm 0.5 \times 10^{23} \mathrm{~cm}^{-3}$ and $\mu_{H}=0.12 \pm$ $0.06 \mathrm{~cm}^{2} \mathrm{~V}^{-1} \mathrm{~s}^{-1}$ are thickness- and temperature-independent. This $p_{H}$ value is in good agreement with that reported by Lenzlinger et $a l^{33}$ for sputtered amorphous films on oxidized silicon wafer and is significantly higher than the values reported for bulk $\mathrm{CrSi}_{2}\left(p_{H}=4\right.$ to $6 \times 10^{20} \mathrm{~cm}^{-3} 16,44$, ${ }^{45}$ ). Meanwhile, $\mu_{H}$ decreases by two orders of magnitude compared to bulk $\mathrm{CrSi}_{2}$ for which $\mu_{H}=12 \mathrm{~cm}^{2} \mathrm{~V}^{-1} \mathrm{~s}^{-1}{ }^{44}$. This low mobility can be attributed to the structural disorder inherent to amorphous compounds that strongly scatters the charge carriers. After partial crystallization, $p_{H}$ decreases to $6 \times 10^{21} \pm 3 \times 10^{21} \mathrm{~cm}^{-3}$, regardless of the thickness, and remains constant in the temperature range covered. This effect originates from the decrease in the defect concentration induced by crystallization and atomic rearrangement. In contrast, the observed increase in $\mu_{H}$ is no longer thickness-independent. The mobility values increase from 
$\mu_{H}=0.90 \pm 0.09 \mathrm{~cm}^{2} \mathrm{~V}^{-1} \mathrm{~s}^{-1}$ to $\mu_{H}=1.40 \pm 0.16 \mathrm{~cm}^{2} \mathrm{~V}^{-1} \mathrm{~s}^{-1}$ for 12 and $164 \mathrm{~nm}$ thick films, respectively. These values remain substantially lower than those measured in the bulk counterpart. It should be noted that $\mu_{H}$ values in $\mathrm{CrSi}_{2}$ are highly related to the defect concentration as shown by Zhu et al ${ }^{46}$ who obtained $\mu_{H}=1085 \mathrm{~cm}^{2} \mathrm{~V}^{-1} \mathrm{~s}^{-1}$ for epitaxial films due to a lower defect concentration compared to the present sputtered amorphous and nanostructured films.

\subsubsection{Influence of film thickness on the electrical resistivity}

Figure 5 shows the evolution of the electrical resistivity as a function of temperature for amorphous and nanostructured thin films deposited on $\mathrm{Si}(100)$ wafers with $\mathrm{SiO}_{2}$ sublayer with a thickness varying from 12 to $164 \mathrm{~nm}$. For amorphous films, $\rho$ increases with decreasing the thickness over the entire temperature range. This behavior is characteristic of charge carrier scattering at the film surface, as previously observed for example for $\mathrm{Cu}^{47}, \mathrm{~W}^{48}, \mathrm{Mo}^{49}$ or $^{\mathrm{CrSi}_{2}}$ amorphous thin films ${ }^{12}$. In contrast, the thickness effect is less significant for nanostructured thin films. This different behavior cannot be explained by the surface roughness as similar $R_{m s}$ values were measured for both films (see Figure 2). For this reason, we believe that charge carrier scattering mechanisms at the film surface are equivalent in both films. Nevertheless, the formation of nano-crystallites in the annealed thin film likely leads to an additional scattering mechanism at the amorphous matrix / nano-crystallite interface. 

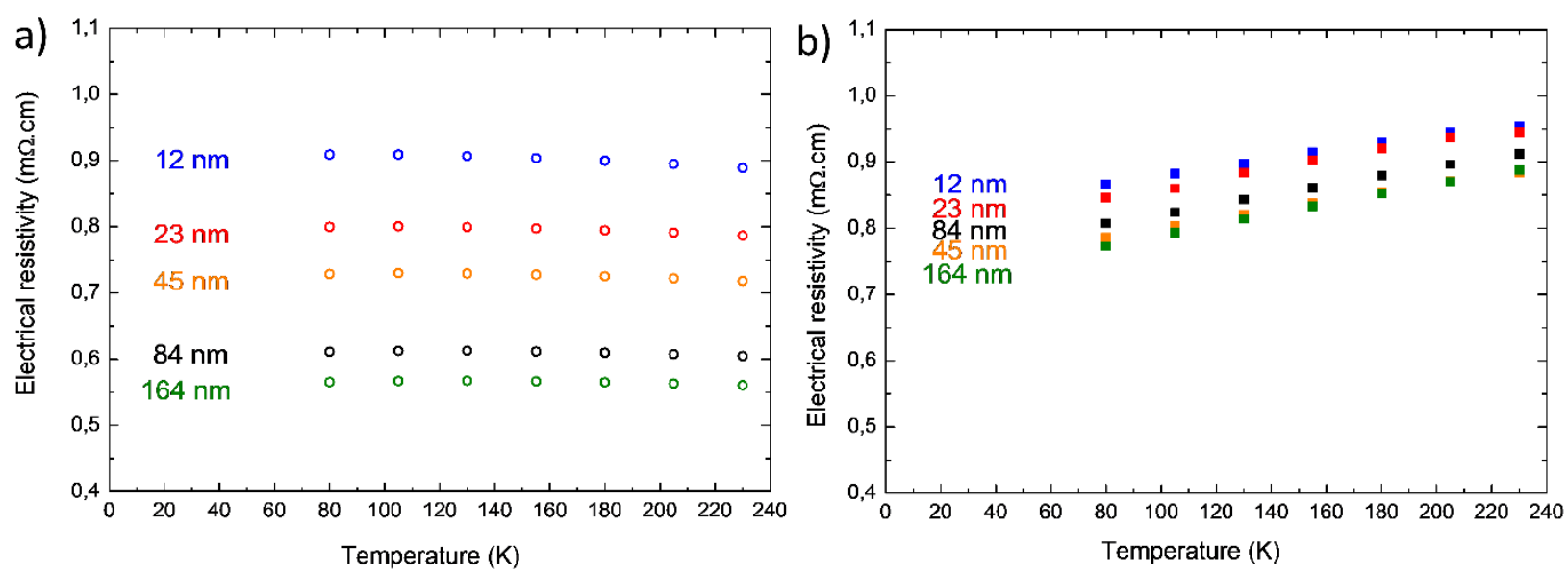

Figure 5. Evolution of the electrical resistivity $\rho$ with the thickness of the $\mathrm{CrSi}_{2}$ film for a) amorphous and b) nanostructured thin films.

To explain this behavior, we considered the well-known Fuchs-Sondheimer (F-S) model, which is based on the Boltzmann transport equation ${ }^{50}$. This model is generally used to describe surface scattering of electrons in metallic thin films, and can be extended to semiconducting thin films by neglecting surface states within the flat-band approximation ${ }^{51}$. The F-S model, which assumes a single parabolic conduction band, a thickness-independent structural disorder, plane parallel surfaces and isotropic scattering processes ${ }^{52}$, yields the following equation:

$$
\frac{\rho_{\infty}}{\rho}=1-\frac{3(1-p)}{2 K} \int_{1}^{\infty}\left(\frac{1}{t^{3}}-\frac{1}{t^{5}}\right) \frac{1-e^{-K t}}{1-p e^{-K t}} d t
$$

where $\rho_{\infty}$ is the electrical resistivity of an infinitely thick film with the same microstructure (including contributions from phonons, grain boundaries, impurities or point-defect scattering mechanisms), $K=d / \lambda_{e}$ where $d$ is the film thickness and $\lambda_{e}$ is the charge carrier mean free path in a bulk material with the same defect and impurity concentrations, and $p(0 \leq p \leq 1)$ is the specularity coefficient describing the fraction of electrons that are specularly scattered from the surface. These scattered electrons have a conserved momentum and hence, do not contribute 
to the electrical resistivity. In contrast, in the case of totally diffused scattering $(p=0)$, all the electrons are scattered with a random direction resulting in increased electrical resistivity.

In the present study, we tried to apply this approach to model the low-temperature experimental data measured on amorphous and nanostructured thin films. These data were fitted by a least-squares method using the Gauss-Newton algorithm to evaluate the values of $\rho_{\infty}$ and $\lambda_{e}$. Within this model, however, the value of $p$ is usually unknown and strongly depends on the deposition method and substrate ${ }^{53}$. In the case of copper thin films, for instance, Marom et al. ${ }^{54}$ have shown that the scattering of electrons on smooth surfaces (that is, below the de Broglie wavelength) is mostly specular, synonymous with $p$ values close to 1 . In the present case, the $R_{m s}$ values of the $\mathrm{CrSi}_{2}$ thin films are low, varying from 0.5 to $0.8 \mathrm{~nm}$ and from 0.7 to $1.2 \mathrm{~nm}$ for amorphous and nanostructured thin films, respectively, that is, below the de Broglie wavelength of $\mathrm{CrSi}_{2}$ estimated to be $5 \mathrm{~nm}^{55}$. Based on this empirical criterion, we may therefore expect a mostly specular diffusion scattering in both cases, giving rise to high $p$ values. Both $p$, and $\lambda_{e}$ parameters cannot be independently determined by the F-S model ${ }^{56,57}$. Due to the lack of direct experimental probes to easily determine $p$, a totally diffused scattering with $p=0$ is usually assumed in the literature ${ }^{12,57-59}$. For these reasons, we have implemented this model with several values of $p$ varying from 0 to 1 . As illustrative examples of the quality of the fits obtained, similar across the entire temperature range and for each $p$ value, Figures $6 \mathrm{a}$ and $6 \mathrm{~b}$ show the results obtained at 80 and $205 \mathrm{~K}$ assuming $p=0$.

In the case of amorphous thin films, surface scattering occurs for thicknesses below about 45 $\mathrm{nm}$ (Figure $6 \mathrm{a}$ and $6 \mathrm{~b}$ ), thereby increasing the electrical resistivity of thinner films. This value is in good agreement with the thickness limit of $40 \mathrm{~nm}$ reported by Novikov et al. ${ }^{32}$. The estimated values of $\rho_{\infty}$ at each temperature are reported in Figure $6 \mathrm{c}$ and are similar for $p$ value ranging 
from 0 to 1 (Figure S2). The value of $\rho_{\infty}=0.56 \mathrm{~m} \Omega$.cm does not depend on temperature, which is consistent with the amorphous nature of the film, as previously discussed. In contrast, $\lambda_{e}$ strongly depends on $p$, as shown in Figure 6d, resulting in charge carrier mean free paths that increase with increasing $p$, from $\lambda_{e} \approx 15 \mathrm{~nm}$ for $p=0$ up to $\lambda_{e} \approx 40 \mathrm{~nm}$ for $p=0.5$. These values are similar across the entire temperature range covered. A wide range of electron mean free paths in amorphous metallic films were reported in literature, ranging from $3 \mathrm{~nm}$ in $\mathrm{Co}_{94} \mathrm{Zr}_{6}$ films ${ }^{58}$ (at $300 \mathrm{~K}$, with $p=0$ ) to $18-30 \mathrm{~nm}^{60}$ in $\mathrm{Y}$ films (at $4.2 \mathrm{~K}$, determined using another model) through $10-13 \mathrm{~nm}{ }^{61}$ in Pt films (at $300 \mathrm{~K}$, with $p$ varying from 0.13 to 0.15 ). Based on these reported values, the large mean free paths obtained herein for higher $p$ values, up to $\lambda_{e}=$ $240 \mathrm{~nm}$ for $p=0.9$, are unrealistic. For this reason, we have restricted our analysis to values of $p$ near 0 . These considerations thus suggest that diffused scattering of charge carriers prevails in amorphous films despite their low roughness, with $\lambda_{e} \geq 15 \mathrm{~nm}$.

For nanostructured thin films, the values of $\rho_{\infty}$ are higher compared to amorphous thin films and slightly increase with increasing temperature (Figure $6 \mathrm{c}$ ) from $0.78 \mathrm{~m} \Omega . \mathrm{cm}$ at $80 \mathrm{~K}$ to 0.89 $\mathrm{m} \Omega . \mathrm{cm}$ at $255 \mathrm{~K}$ (without any dependence on $p$ ). Figure $6 \mathrm{~d}$ shows that the charge carrier mean free path is reduced for each value of $p$, compared to the amorphous thin films, with, for instance, $\lambda_{e}$ decreasing from $15 \mathrm{~nm}$ to $3 \mathrm{~nm}$ if $p=0$. We note that these values are in good agreement with the value of $\lambda_{e}=2 \mathrm{~nm}$ inferred by Trofimov et al. assuming $p=0{ }^{12}$ for nanocrystallized $\mathrm{CrSi}_{2}$ thin films with thicknesses of up to $20 \mathrm{~nm}$ and crystallite sizes varying from 25 to $100 \mathrm{~nm}$. The reduction in the charge carrier mean free path can be explained by the formation of nano-crystallites with sizes comparable to $\lambda_{e}$ that induce additional charge carrier scattering at the nano-crystallites / amorphous phase interfaces. 
The fact that a decrease in the charge carrier density is partially responsible for the increase in $\rho_{\infty}$, and that the charge carriers mean free path is significantly reduced by scattering at the nanocrystallites / amorphous phase interfaces, explains why $\rho$ is less influenced by the film thickness.
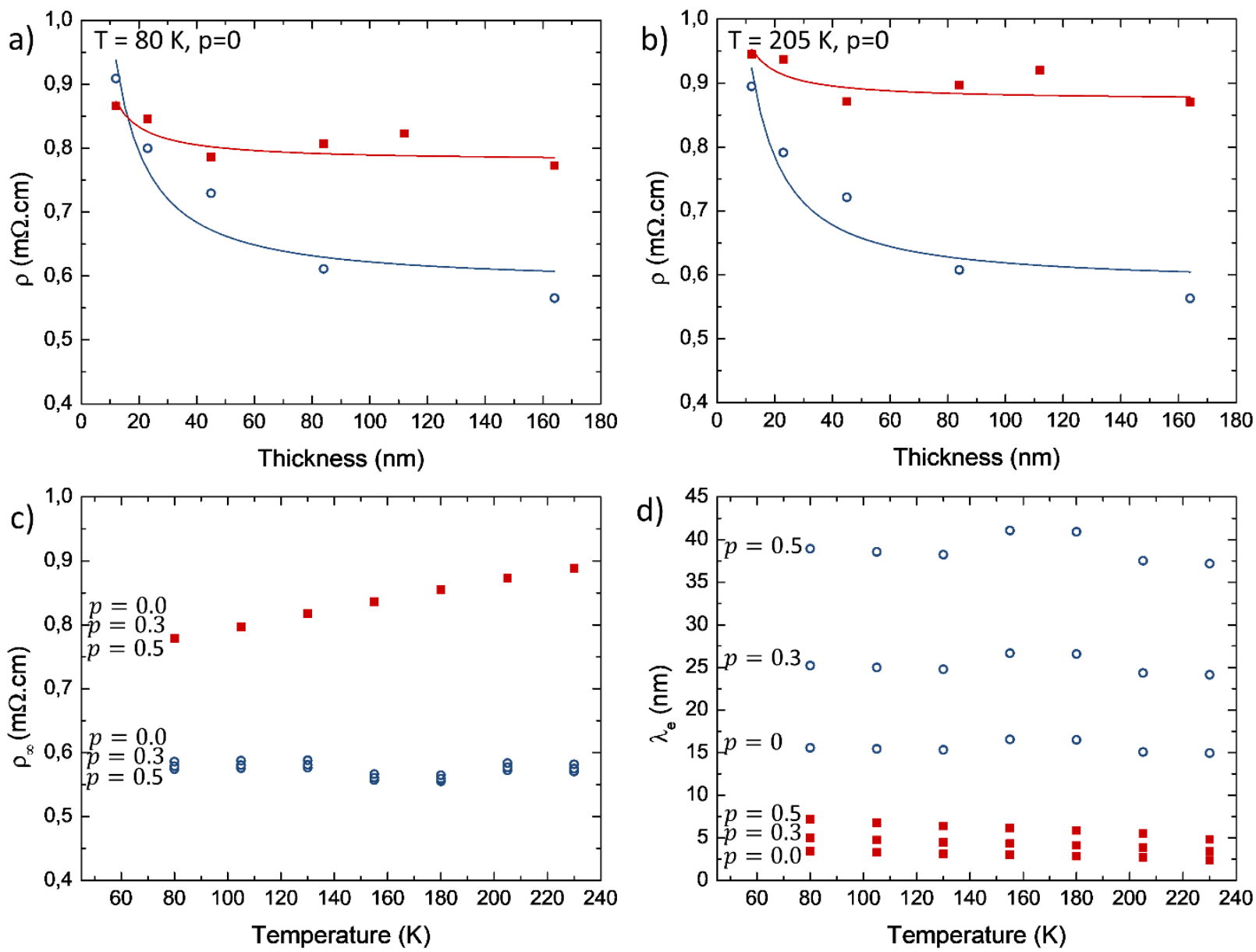

Figure 6. Experimental data (points) and fitted model (lines) of the electrical resistivity $\rho$ as a function of the film thickness for amorphous and nanostructured thin films for $p=0$ at a) $80 \mathrm{~K}$ and b) $205 \mathrm{~K}$. c) $\rho_{\infty}$ values and d) $\lambda_{e}$ values as a function of temperature for amorphous and nanostructured thin films with $p=0, p=0.3$ and $p=0.5$. In the case of $\rho_{\infty}$ the points are nearly identical for each $p$ value and cannot be clearly distinguished. $\bigcirc$ Amorphous films Nanostructured films. 


\subsubsection{Electronic structure}

The optical electronic bandgaps, $E_{g}^{o p t}$, of the thin films have been determined by IR reflectance and transmittance measurements for thin film with a thickness of $161 \mathrm{~nm}$ deposited on a $\mathrm{CaF}_{2}$ substrate. The direct and indirect optical bandgap values have been determined using Tauc plots, a representation particularly well adapted for amorphous and nano-crystalline materials $^{62}$ :

$$
(\alpha h v)^{n}=\beta\left(h v-E_{g}^{o p t}\right)
$$

where $\alpha$ is the absorption coefficient, $\beta$ is the band tailing parameter, $h v$ is the incoming photon energy, and $n$ is a constant related to the transition process $(n=1 / 2$ and $n=2$ for indirect and direct transitions, respectively). Numerous models are used for the determination of $\alpha$ from experimental reflectance and transmittance measurements depending on the experimental conditions. After comparison of some models, we used the method of Galkin et al. ${ }^{63}$, the details of which are given in the Supporting Information Part 3. This model is adapted in the case of an absorbing thin film and considering multiple reflections in the thickness of the film and the substrate. The inferred values of $\alpha$ with the corresponding Tauc plots are shown in Figures $7 \mathrm{a}$ and $7 \mathrm{~b}$. A steep increase in $\alpha$ can be observed for photon energies above 0.23 and $0.43 \mathrm{eV}$ for amorphous and nanostructured $\mathrm{CrSi}_{2}$ thin films, respectively (Figure 7a). It clearly indicates a semiconducting nature of both materials, while a metallic behavior of amorphous $\mathrm{CrSi}_{2}$ films was suggested based solely on electrical resistivity measurements $22,29,34,64$. The non-zero absorption at low energies can be attributed to extrinsic absorption from free carriers. Tauc plots (Figure $7 \mathrm{~b}$ ) show that amorphous and nanostructured $\mathrm{CrSi}_{2}$ thin films have indirect band gaps of $E_{\text {g,ind }}^{o p t}=0.15 \pm 0.01 \mathrm{eV}$ and $E_{g, \text { ind }}^{o p t}=0.20 \pm 0.01 \mathrm{eV}$, respectively, and direct band gaps of $E_{g, \text { dir }}^{o p t}=0.59 \pm 0.01 \mathrm{eV}$ and $E_{g, \text { dir }}^{o p t}=0.63 \pm 0.01 \mathrm{eV}$. The errors have been estimated from the 
linear regression dependence on the selected data range. Thus, amorphous $\mathrm{CrSi}_{2}$ thin films show a very low band gap value explaining the low electrical resistivity and nearly-metallic behavior. An increase in the band gap can be observed upon partial crystallization, although the value is not equivalent to that of crystallized $\mathrm{CrSi}_{2}\left(\sim 0.35 \mathrm{eV}^{10}\right)$. This modified electronic structure is in agreement with the increase in the electrical resistivity and decrease in the charge carrier concentration measured experimentally, which can be attributed to the reduction of defect level and nano-crystallization during the annealing process. Such changes of the electronic structure of $\mathrm{CrSi}_{2}$ thin films due to nano-crystallization are consistent with previous optical conductivity measurements ${ }^{22}$.

In contrast to crystalline materials that exhibit well-defined band gap edges, amorphous materials can be characterized by band tails due to structural defects ${ }^{65}$. They are quantified by the Urbach energy, $E_{u}$, inferred from the exponential part of the absorption coefficient near the gap using the relation $\alpha=\alpha_{0} \exp \left(\frac{h v}{E_{u}}\right)$. The value of $E_{u}$ corresponds to the width of the tails of localized states near the band edge and are obtained from the plot of the variations in $\ln (\alpha)$ with $h v$ near the bandgap (see Supporting Information Part 4). Herein, a dramatic decrease of $E_{u}$ by nano-crystallization is observed with values of $E_{u}$ of $0.13 \mathrm{eV}$ and $0.06 \mathrm{eV}$ for as-deposited and annealed films, respectively, due to a decrease in the defect level. Thus, these band tails, nearly identical to the band gap values, can explain the quasi-metallic behavior of the amorphous thin films. 

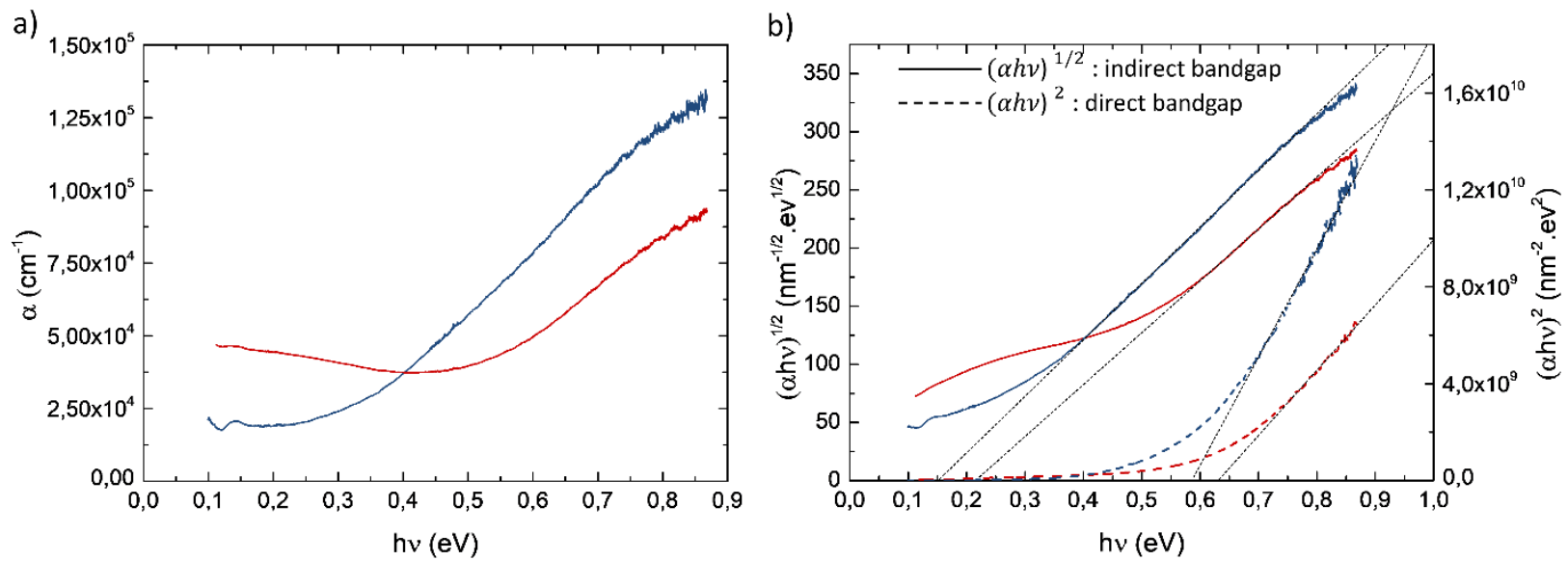

Figure 7. Optical properties of amorphous (as-deposited) and nanostructured (annealed) $\mathrm{CrSi}_{2}$ thin films. a) Absorption coefficient and b) corresponding Tauc plot for both indirect and direct band gaps. $\square$ Amorphous film, $\square$ Nanostructured film. The black dashed lines show the linear fit of the Tauc plot.

\subsection{Optical properties of amorphous and nanostructured $\mathrm{CrSi}_{2}$ thin films}

The refractive index, $n$, and extinction coefficient, $k$, shown in Figure $8 \mathrm{a}$, were determined from the IR absorbance coefficients (see Figure 7a). The observed variations are in line with the electronic structure modifications induced by the nano-crystallization.

The behavior of $n$ agrees with those reported for well-crystallized or epitaxial films and single crystals ${ }^{10,63,66}$. A broad maximum is observed around $0.16-0.25 \mathrm{eV}$ and $0.43-0.53 \mathrm{eV}$ for asdeposited and annealed films, respectively. These energy windows are consistent with those reported in the literature for well-crystallized $\mathrm{CrSi}_{2}$ thin films, extending from $0.3-0.55 \mathrm{eV}^{10}$ to $0.47-0.56 \mathrm{eV}^{63}$. The energy shift of the maximum in $n$ upon annealing is directly related to electronic structure modifications due to the change of inter-band transition as the band gap increases. Moreover, a large reduction of $n$ values is observed after nano-crystallization, as expected from an increase in the band gap. Nevertheless, the $n$ values of annealed $\mathrm{CrSi}_{2}$ thin 
films are still higher than those reported previously ${ }^{10,63,66}$ because of the partial crystallization of the material after the thermal treatment. As for $k$, both amorphous and nanostructured samples show a similar behavior with a shift of about $0.25 \mathrm{eV}$. A large increase in $k$ with decreasing the energy is observed, due to the absorption by free charge carriers ${ }^{10}$. The slope of this part is higher for the amorphous thin film due to the high defect concentration. A minimum value of $k \approx 0.8$ is observed around $0.3 \mathrm{eV}$ and $0.5 \mathrm{eV}$ for amorphous and nanostructured thin films, respectively.

The real $\left(\varepsilon_{1}\right)$ and imaginary $\left(\varepsilon_{2}\right)$ parts of the dielectric function, were calculated from the $n$ and $k$ values using the following relations ${ }^{67}$ :

$$
\begin{gathered}
\varepsilon_{1}=n^{2}-k^{2} \\
\varepsilon_{2}=2 n k
\end{gathered}
$$

The $\varepsilon_{1}$ and $\varepsilon_{2}$ values, reported in Figure $8 \mathrm{~b}$, are analogous with $n$ and $k$. Broad maxima of $\varepsilon_{1}$ are observed at $0.16-0.25 \mathrm{eV}$ and $0.43-0.53 \mathrm{eV}$ for amorphous and nanostructured thin films, respectively, due to inter-band transitions. The $\varepsilon_{1}$ values are nevertheless larger in the case of the amorphous thin films. As for $\varepsilon_{2}$, a large increase is observed at low energies, as previously described in the case of $k$.

Similarly to our results on nanostructured film, a maximum in $\varepsilon_{1}$ at about $0.5 \mathrm{eV}$ is reported for epitaxial and polycrystalline $\mathrm{CrSi}_{2}$ films ${ }^{63,66}$, but with a smaller $\varepsilon_{1}$ value (near 50) due to the residual amorphous phase in our sample. 

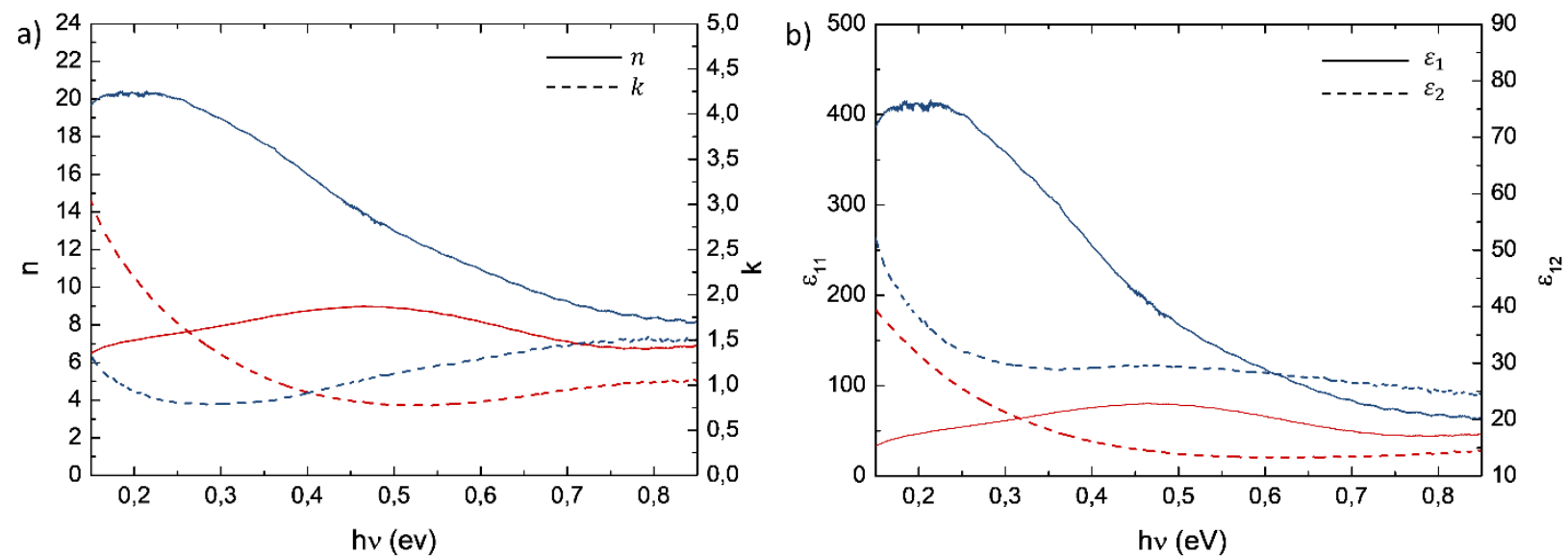

Figure 8. a) Refractive index $n$ and extinction coefficient $k$ as a function of the photon energy $h v$. b) Real and imaginary parts of the dielectric function $\varepsilon_{1}$ and $\varepsilon_{2}$ as a function of the photon energy. $\square$ Amorphous (as-deposited) and $\square$ Nanostructured (annealed) thin films.

\section{Conclusion}

Contrasting the electrical, vibrational and optical properties of as-deposited, amorphous and annealed, nanostructured $\mathrm{CrSi}_{2}$ thin films have revealed interesting insights into the influence of nano-crystallites, successfully grown in the amorphous matrix through annealing for $1 \mathrm{~h}$ at $723 \mathrm{~K}$ under vacuum. Raman spectroscopy has evidenced a line at $229 \mathrm{~cm}^{-1}$, predicted to be a $\mathrm{E}_{1}$ mode by DFT calculations, that had remained elusive so far in experiments on thin films. In agreement with first-principles calculations, these measurements further enabled the identification of a weak Raman line at $248 \mathrm{~cm}^{-1}$, which had been previously observed solely on polycrystalline $\mathrm{CrSi}_{2}$, but with a significantly lower intensity. The presence of high defect concentrations in amorphous films, acting as acceptor dopants, significantly increases the hole concentration to values usually encountered in metals. The amorphous nature of these films explains the strong lowering of the band gap width evidenced by optical spectra $\left(E_{g, \text { ind }}^{\text {opt }}=0.15 \pm 0.01\right)$ due to band tails that cover 
nearly entirely the band gap $\left(E_{u}=0.13 \mathrm{eV}\right)$. Upon annealing, the nano-crystallization induces a decrease in the defect concentration, leading to a concomitant increase in the band gap and reduction in the band tail width, in agreement with the measured lower carrier concentration. Thus, the increase in the electrical resistivity in partially-crystallized thin films can be explained by both the reduction of defect concentration by annealing, which modifies the electronic structure, and the formation of nano-crystallites that promotes an additional interface scattering mechanism reducing the charge carrier mean free path. Using the Fuchs-Sondheimer model, we showed that a charge carrier mean free path of $\lambda_{e} \geq 15 \mathrm{~nm}$ in amorphous films is responsible for the variations in electrical properties as a function of the thickness by surface scattering that dominates for thicknesses below $45 \mathrm{~nm}$. The variations in the electronic structure also manifest in the optical and dielectric constants. The decrease in the band gap in amorphous thin films produces a shift of the $n, k, \varepsilon_{1}$ and $\varepsilon_{2}$ constants towards low energy and a modification of their intensities. A large index of refraction $n$ in the mid-IR range was obtained for amorphous $\mathrm{CrSi}_{2}$ thin films, which can be of practical relevance to form waveguides for instance. Our study provides a robust basis to understand the vibrational, electronic and optical properties of both amorphous and nanostructured $\mathrm{CrSi}_{2}$ thin films. In particular, our results demonstrate the

possibility to tailor the electrical, optical and vibrational properties by controlling the crystallization rate during annealing and the thickness of the thin films for a given application.

\section{ASSOCIATED CONTENT}

\section{Supporting Information}

Atomic Force Microscopy (AFM) observations, details of the Fuchs-Sondheimer model, absorption coefficient calculation and Urbach energy determination. 


\section{AUTHOR INFORMATION}

\section{Corresponding Author}

Adrien Moll - Institut Charles Gerhardt Montpellier, UMR5253, CNRS, Université de Montpellier, Montpellier 34095, France ; Email : moll@icmpe.cnrs.fr

Nicole Fréty - Institut Charles Gerhardt Montpellier, UMR5253, CNRS, Université de Montpellier, Montpellier 34095, France ; Email : nicole.frety@umontpellier.fr

\section{Present Addresses}

Adrien Moll - now at Univ. Paris Est Creteil, CNRS, ICMPE, UMR 7182, Thiais 94320, France

\section{Author Contributions}

The manuscript was written through contributions of all authors. All authors have given approval to the final version of the manuscript. The authors contributed equally.

\section{ACKNOWLEDGMENT}

The authors would like to greatly acknowledge Dr R. Viennois for fruitful discussions. Thin films were prepared at the Centrale de Technologie en Micro et nanoélectronique (CTM), Université de Montpellier, France. The authors would like to particularly thank F. Pichot for his precious help. They also thank D. Troadec (IENM, Lille, France) for the FIB sample preparation. This work was partly supported by the French RENATECH network. The authors also thank L. Daenes for Raman spectroscopy measurements performed at the Plateforme d'Analyse et de 
Caractérisation Chimie Balard, Montpellier, France. Infrared Reflectance experiments were performed at the IR-Raman technological platform of the Université de Montpellier, France.

\section{References}

1. Murarka, S. P. Silicides for VLSI Applications; Academic Press, 2012.

2. Reader, A. H.; Van Ommen, A. H.; Weijs, P. J. W.; Wolters, R. A. M.; Oostra, D. J. Transition Metal Silicides in Silicon Technology. Rep. Prog. Phys. 1993, 56, 1397.

3. Chen, S.-Y.; Yeh, P.-H.; Wen-Wei Wu, W.-W.; Chen, U.-S.; Chueh, Y.-L.; Yang, Y.-C.; Gwo, S.; Chen, L.-J. Low Resistivity Metal Silicide Nanowires with Extraordinarily High Aspect Ratio for Future Nanoelectronic Devices. ACS Nano 2011, 5, 9202-9207.

4. Lange, H. Electronic Properties of Semiconducting Silicides. Phys. Status Solidi B 1997, $201,3-65$.

5. Mühlbauer, S.; Binz, B.; Jonietz, F.; Pfleiderer, C.; Rosch, A.; Neubauer, A.; Georgii, R.; Böni, P. Skyrmion Lattice in a Chiral Magnet. Science 2009, 323, 915-919.

6. $\quad$ Takane, D.; Wang, Z.; Souma, S.; Nakayama, K.; Nakamura, T.; Oinuma, H.; Nakata, Y.; Iwasawa, H.; Cacho, C.; Kim, T., et al. Observation of Chiral Fermions with a Large Topological Charge and Associated Fermi-Arc Surface States in CoSi. Phys Rev Lett 2019, 122, 076402.

7. Pshenay-Severin, D. A.; Ivanov, Y. V.; Burkov, A. A.; Burkov, A. T. Band Structure and Unconventional Electronic Topology of CoSi. J. Phys.: Condens. Matter 2018, 30, 135501.

8. Ma, J.; Gu, Y.; Shi, L.; Chen, L.; Yang, Z.; Qian, Y. Synthesis and Thermal Stability of Nanocrystalline Chromium Disilicide. J. Alloys Compd. 2004, 376, 176-179.

9. Stathokostopoulos, D.; Chaliampalias, D.; Tarani, E.; Theodorakakos, A.; Giannoulatou, V.; Polymeris, G. S.; Pavlidou, E.; Chrissafis, K.; Hatzikraniotis, E.; Paraskevopoulos, K. M., et 
al. Formation of the Thermoelectric Candidate Chromium Silicide by Use of a PackCementation Process. J. Electron. Mater. 2014, 43, 3733-3739.

10. Bost, M. C.; Mahan, J. E. An Investigation of the Optical Constants and Band Gap of Chromium Disilicide. J. Appl. Phys 1988, 63, 839-844.

11. Lange, H.; Giehler, M.; Henrion, W.; Fenske, F.; Sieber, I.; Oertel, G. Growth and Optical Characterization of $\mathrm{CrSi}_{2}$ Thin Films. Phys. Status Solidi B 1992, 171, 63-76.

12. Trofimov, V. I.; Kim, J.; Bae, S. Effect of Deposition Conditions on the Structure, Phase Composition and Electrical Properties of the Chromium Silicide Films. J. Phys.: Conf. Ser. 2008, $100,042015$.

13. Hieber, K.; Dittmann, R. Structural and Electrical Properties of $\mathrm{CrSi}_{2}$ Thin Film Resistors. Thin Solid Films 1976, 36, 357-360.

14. Waits, R. K. Sputtered Silicon-Chromium Resistive Films. J. Vac. Sci. Technol. 1969, 6, 308-315.

15. Fedorov, M. I.; Zaitsev, V. K. In Thermoelectrics Handbook-Macro to Nano; Rowe, D. M., Ed.; Taylor \& Francis Group, LLC, 2006; Chap. 31-1 - 31-3.

16. Nishida, I. The Crystal Growth and Thermoelectric Properties of Chromium Disilicide. $J$. Mater. Sci. 1972, 7, 1119-1124.

17. Goroshko, D.; Chusovitin, E.; Shevlyagin, A.; Bozhenko, M.; Batalov, R.; Bayazitov, R.; Galkin, N. Enhancement of Near IR Sensitivity of Silicon-Silicide Based Photodetectors. Phys. Status Solidi C 2013, 10, 1844-1846.

18. Migas, D. B.; Borisenko, V. E. Semiconducting Silicides as Potential Candidates for Light Detectors: Ab Initio Predictions. Phys. Status Solidi C 2013, 10, 1658-1660. 
19. Chang, M.-T.; Chen, C.-Y.; Chou, L.-J.; Chen, L.-J. Core-Shell Chromium SilicideSilicon Nanopillars: A Contact Material for Future Nanosystems. ACS Nano 2009, 3, 3776-3780.

20. Aniltürk, Ö. S.; Turan, R. Electrical Transport at a Non-Ideal $\mathrm{CrSi}_{2}$-Si Junction. SolidState Electron. 2000, 44, 41-48.

21. Barus, M.; Donoval, D. Analysis if $I-V$ Measurements on $\mathrm{CrSi}_{2}-\mathrm{Si}$ Schottky Structures in a Wide Temperature Range. Solid-State Electron. 1993, 37, 969-974.

22. Luches, A.; Mulenko, S. A.; Veiko, V. P.; Caricato, A. P.; Chuiko, V. A.; Kudryavtsev, Y. V.; Lopato, A. V.; Petrov, A. A.; Romano, F.; Valerini, D. Laser-Assisted Synthesis of Semiconductor Chromium Disilicide Films. Appl. Surf. Sci. 2007, 253, 6512-6516.

23. Galkin, N. G.; Velitchko, T. V.; Skripka, S. V.; Khrustalev, A. B. Semiconducting and Structural Properties of $\mathrm{CrSi}_{2}$ A-Type Epitaxial Films on Si( 111 ). Thin Solid Films 1996, 280, 211-220.

24. Burkov, A. T.; Novikov, S. V.; Khovaylo, V. V.; Schumann, J. Energy Filtering Enhancement of Thermoelectric Performance of Nanocrystalline $\mathrm{Cr}_{1-\mathrm{x}} \mathrm{Si}_{\mathrm{x}}$ Composites. J. Alloys Compd. 2017, 691, 89-94.

25. Abd El Qader, M.; Venkat, R.; Kumar, R.; Hartmann, T.; Ginobbi, P.; Newman, N.; Singh, R. Structural, Electrical, and Thermoelectric Properties of $\mathrm{CrSi}_{2}$ Thin Films. Thin Solid Films 2013, 545, 100-105.

26. Gong, S. F.; Li, X. H.; Hentzell, H. T. G.; Strandberg, J. Electrical and Structural Properties of Thin Film of Sputtered CrSi 2 . Thin Solid Films 1992, 208, 91-95.

27. Koudelka, L.; Lustig, N.; Lannin, J. S. Raman Scattering of Ni and Cr Amorphous Disilicides. Solid State Commun. 1987, 63, 163-166. 
28. Novikov, S. V.; Burkov, A. T.; Schumann, J. Enhancement of Thermoelectric Properties in Nanocrystalline M-Si Thin Film Composites (M=Cr, Mn). J. Alloys Compd. 2013, 557, 239243.

29. Nava, F.; Tien, T.; Tu, K. N. Temperature Dependence of Semiconducting and Structural Properties of Cr- Si Thin Films. J. Appl. Phys 1985, 57, 2018-2025.

30. Caricato, A. P.; Leggieri, G.; Luches, A.; Romano, F.; Barucca, G.; Mengucci, P.; Mulenko, S. A. Morphological and Structural Characterizations of $\mathrm{CrSi}_{2}$ Nanometric Films Deposited by Laser Ablation. Appl. Surf. Sci. 2007, 254, 1224-1227.

31. Gladun, C.; Heinrich, A.; Schumann, J.; Pitschke, W.; Vinzelberg, H. Transport Properties of Nanodisperse $\mathrm{Cr}_{\mathrm{x}} \mathrm{Si}_{1-\mathrm{x}}$ Thin Films. Int. J. Electron. 1994, 77, 301-308.

32. Novikov, S. V.; Burkov, A. T.; Schumann, J. Crystallization and Transport Properties of Amorphous Cr-Si Thin Film Thermoelectrics. J. Electron. Mater. 2014, 43, 2420-2424.

33. Lenzlinger, M.; O'Keefe, G. Hall Effect in Silicon-Chromium Films. J. Appl. Phys 1969, 40, 4913-4919.

34. Kim, C.-G. Electrical Properties of $\mathrm{CrSi}_{x}, \mathrm{Cr} / \mathrm{CrSi}_{x} / \mathrm{Cr} / \mathrm{CrSi}_{x}$, and $\mathrm{CrSi}_{x} / \mathrm{Si}^{\prime} / \mathrm{CrSi}_{x} / \mathrm{Si}$ Sputtered on Alumina Plates. Thin Solid Films 2005, 479, 182-187.

35. Kim, K. C.; Lim, S. S.; Lee, S. H.; Hong, J.; Cho, D. Y.; Mohamed, A. Y.; Koo, C. M.; Baek, S. H.; Kim, J. S.; Kim, S. K. Precision Interface Engineering of an Atomic Layer in Bulk $\mathrm{Bi}_{2} \mathrm{Te}_{3}$ Alloys for High Thermoelectric Performance. ACS Nano 2019, 13, 7146-7154.

36. Vineis, C. J.; Shakouri, A.; Majumdar, A.; Kanatzidis, M. G. Nanostructured Thermoelectrics: Big Efficiency Gains From Small Features. Adv. Mater. 2010, 22, 3970-80. 
37. Hermet, P.; Khalil, M.; Viennois, R.; Beaudhuin, M.; Bourgogne, D.; Ravot, D. Revisited Phonon Assignment and Electro-Mechanical Properties of Chromium Disilicide. $R S C A d v$. 2015, $5,19106$.

38. Nečas, D.; Klapetek, P. Gwyddion: an Open-Source Software for SPM Data Analysis. Open Phys. 2012, 10.

39. Borghesi, A.; Piaggi, A.; Franchini, A.; Guizzetti, G.; Nava, F.; Santoro, G. Far-Infrared Vibrational Spectroscopy in $\mathrm{CrSi}_{2}$. Europhys. Lett. 1990, 11, 61-65.

40. Chaix-Pluchery, O.; Lucazeau, G. Vibrational Study of Transition Metal Disilicides, $\mathrm{MSi}_{2}(\mathrm{M}=\mathrm{Nb}, \mathrm{Ta}, \mathrm{V}, \mathrm{Cr})$. J. Raman Spectrosc. 1998, 29, 159-164.

41. Rao, K. V. In Amorphous Metallic Alloys; Luborsky, F. E., Ed.; Butterworth \& Co, 1983; Chap. 21.

42. Dasgupta, T.; Etourneau, J.; Chevalier, B.; Matar, S. F.; Umarji, A. M. Structural, Thermal, and Electrical Properties of $\mathrm{CrSi}_{2}$. J. Appl. Phys 2008, 103, 113516.

43. Nishida, I.; Sakata, T. Semiconducting Properties of Pure and Mn-Doped Chromium Disilicide. J. Phys. Chem. Solids 1978, 39, 499-505.

44. Shinoda, D.; Asanabe, S.; Sasaki, Y. Semiconducting Properties of Chromium Silicides. J. Phys. Soc. Jpn. 1964, 19, 269-272.

45. Voronov, B. K.; Dudkin, L. D.; Kiryukhina, N. I.; Trusova, N. N. A Physicochemical Study of a Chromium Disilicide-Based Phase. Izv. Akad. Nauk SSSR, Neorg. Mater. 1968, 4, 325-330.

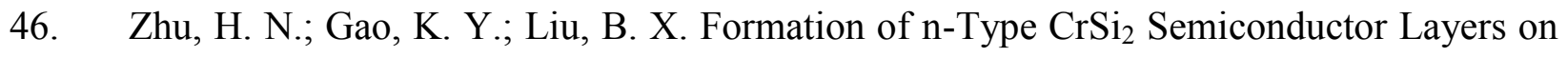
Si by High-Current Cr Ion Implantation. J. Phys. D: Appl. Phys. 2000, 33, L49-L52. 
47. Zhou, T.; Gall, D. Resistivity Scaling Due to Electron Surface Scattering in Thin Metal Layers. Phys. Rev. B 2018, 97.

48. Choi, D.; Barmak, K. On the Potential of Tungsten as Next-Generation Semiconductor Interconnects. Electron. Mater. Lett. 2017, 13, 449-456.

49. Schmid, U.; Seidel, H. Effect of Substrate Properties and Thermal Annealing on the Resistivity of Molybdenum Thin Films. Thin Solid Films 2005, 489, 310-319.

50. Fuchs, K.; Wills, H. H. The Conductivity of Thin Metallic Films According to the Electron Theory of Metals. Math. Proc. Cambridge Philos. Soc. 1938, 34, 100-108.

51. Anderson, J. C. Conduction in Thin Semiconductor Films. Adv. Phys. 1970, 19, 311-338.

52. Wißmann, P. In Surface Physics-Springer Tracts in Modern Physics; Höhler, G., Ed.; Springer, 1975; pp 23-25.

53. Kasap, S.; Koughia, C.; Ruda, H. E. In Springer Handbook of Electronic and Photonic Materials; Kasap, S.; Capper, P., Eds.; Springer, 2017; p 31.

54. Marom, H.; Eizenberg, M. The Effect of Surface Roughness on the Resistivity Increase in Nanometric Dimensions. J. Appl. Phys 2006, 99, 123705.

55. Novikov, S. V.; Burkov, A. T. Grain Boundary Scattering Contribution to the Thermopower in Cr-Si Nanocrystalline Films. J. Phys.: Conf. Ser. 2016, 769, 012069.

56. Choi, D.; Kim, C. S.; Naveh, D.; Chung, S.; Warren, A. P.; Nuhfer, N. T.; Toney, M. F.; Coffey, K. R.; Barmak, K. Electron Mean Free Path of Tungsten and the Electrical Resistivity of Epitaxial (110) Tungsten Films. Phys. Rev. B 2012, 86.

57. Milosevic, E.; Kerdsongpanya, S.; Zangiabadi, A.; Barmak, K.; Coffey, K. R.; Gall, D. Resistivity Size Effect in Epitaxial Ru(0001) Layers. J. Appl. Phys 2018, 124, 165105. 
58. Jagielinski, T. Magnetic and Galvanomagnetic Properties of Amorphous CoZr Thin Films. J. Appl. Phys 1987, 61, 3237-3239.

59. Dranenko, A. S.; Dvorina, L. A. Dimensional Dependence of Electric Resistance of Thin $\mathrm{TiB}_{2}$ Films. Powder Metall. Met. Ceram. 1999, 38, 638-640.

60. Kuz'menko, V. M.; Mel'nikov, V. I.; Sudovtsov, A. I. Electron Properties of Amorphic and Crystalline Ytterbium Films. Sov. Phys. JETP 1976, 44, 786-792.

61. Fischer, G.; Hoffmann, H.; Vancea, J. Mean Free Path and Density of Conductance Electrons in Platinum Determined by the Size Effect in Extremely Thin Films. Phys. Rev. B 1980, 22, 6065-6073.

62. Tauc, J. Optical Properties of Solids; Abelès, F. ed.; North-Holland, Amsterdam, 1972.

63. Galkin, N. G.; Maslov, A. M.; Konchenko, A. V. Optical and Photospectral Properties of $\mathrm{CrSi}_{2}$ A-Type Epitaxial Films on Si(111). Thin Solid Films 1997, 311, 230-238.

64. Dvorina, L. A.; Kud', I. V.; Beddis, G.; Bretshnaider, V.; Khelms, K. Special Features of the Crystallization of Thin Films of Silicides of Some Transition Metals. Sov. Powder Metall. Met. Ceram. 1987, 26, 77-81.

65. Baranovski, S. D.; Rubel, O. In Charge Transport in Disordered Solids with Applications in Electronic; Baranovski, S., Ed.; John Wiley \& Sons, 2006; Chap. 2.

66. Bellani, V.; Guizzetti, G.; Marabelli, F.; Piaggi, A.; Borghesi, A.; Nava, F.; Antonov, V. N.; Antonov, V. N.; Jepsen, O.; Andersen, O. K., et al. Theory and Experiment on the Optical Properties of $\mathrm{CrSi}_{2}$. Phys. Rev. B 1992, 46, 9380-9389.

67. Jensen, B. In Handbook of Optical Constants of Solids; Palik, E. D., Ed.; Academic Press, 1998; p 125. 


\section{For Table of Contents Only}

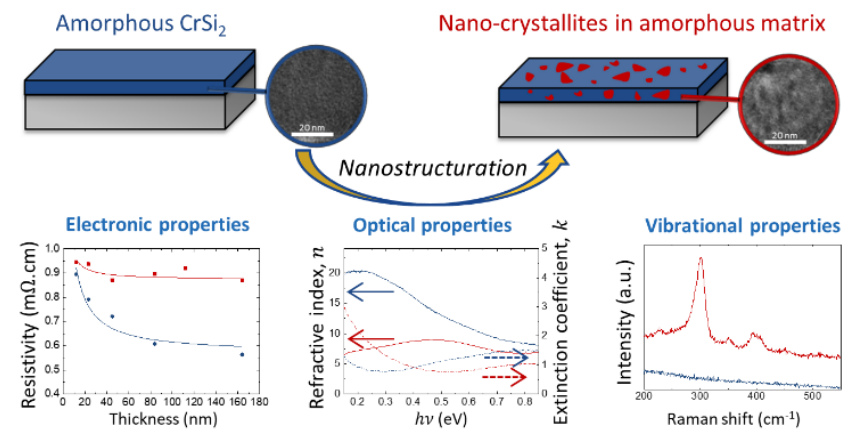

